\title{
Etnoictiologia dos pescadores artesanais da Resex Marinha Caeté- Taperaçu, Pará: aspectos relacionados com etologia, usos de hábitat e migração de peixes da família Sciaenidae
}

\author{
Roberta Sá Leitão Barboza ${ }^{1 *} \&$ Juarez Carlos Brito Pezzuti²
}

${ }^{1}$ Ciências Ambientais, Universidade Federal do Amapá, Rodovia Juscelino Kubischek, s.n., Zerão, Macapá, Amapá, Brasil; e Programa de Pós-graduação em Ecologia Aquática e Pesca, Universidade Federal do Pará, Belém, Pará, Brasil.

${ }^{2}$ Programa de Pós-graduação em Desenvolvimento Sustentável do Trópico Úmido, Núcleo de Altos Estudos Amazônicos, Campus Universitário do Guamá, Rua Augusto Côrrea, 01, 66075-110, Belém, Pará, Brasil.

\begin{abstract}
Resumo - O propósito deste estudo é descrever o conhecimento de pescadores artesanais da vila dos Pescadores e vila Bonifácio (Ajuruteua - Pará) acerca do comportamento, usos de hábitat e migração de peixes da família Sciaenidae. Os resultados apresentados revelam o saber acurado e detalhado dos pescadores de Ajuruteua sobre aspectos do comportamento dos peixes relacionados com fisiologia, reprodução, parasitismo e comensalismo. Os pescadores indicaram também as principais unidades espaciais ocupadas pelos peixes e prováveis razões (bióticas e abióticas) para o deslocamento entre essas unidades. Desta forma, é destacado no presente trabalho o papel fundamental da etnobiologia na obtenção de dados plausíveis para o manejo da pesca a partir do conhecimento de pescadores.

Palavras-chave adicionais: Amazônia, etnobiologia, pesca local, recursos pesqueiros.
\end{abstract}

\begin{abstract}
Ethnoichthyology of traditional fishermen from Caeté-Taperaçu Marine Extractive Reserve: aspects related to ethology, habitat use and migration of fishes of the Sciaenidae) - The purpose of this study was to describe the traditional knowledge of fishermen regarding the behaviour, habitat use and migration of fishes from the Sciaenidae in the villages of Pescadores and Bonifacio (Ajuruteua - Pará). Results show a detailed and accurate knowledge of the Ajuruteua fishermen regarding aspects of fish behaviour, physiology and parasite attack. They also identified the main spatial units occupied by fish, and indicated probable reasons for fish migration within these spatial units. As such, the fundamental role of ethnobiology in the collection of data, that incorporates the popular knowledge of fishermen for fisheries management, is recognized in this study.
\end{abstract}

Additional key words: Amazonia; ethnobiology; local fisheries; fishing resources.

A região amazônica brasileira apresenta um contexto bastante peculiar relacionado à atividade pesqueira. Segundo Barthem \& Fabré (2004), aspectos como riqueza de espécies exploradas, quantidade de pescado capturado e dependência das populações tradicionais fazem da Amazônia uma região de alto potencial pesqueiro, com mobilização de U\$ 200 milhões ano ${ }^{-1}$. Todavia, os modelos de gerenciamento pesqueiro são, em geral, formulados pelo governo com base em informações ecológicas dos recursos e desconsideram a dimensão humana sobre a atividade (Castro 2004).

Nesse contexto, novas propostas de manejo de recursos são assumidas como eficazes à medida que partem do envolvimento dos principais usuários dos recursos em seu gerenciamento, como o comanejo (Sen \& Nielsen 1996; Crampton et al. 2004a; Carlsson \& Berkes 2005; Begossi 2006). Entretanto, a continuidade dos sistemas de manejo comunitário e o design de novas práticas dependem do conhecimento local dos usuários dos recursos (Ruddle 1994). Conhecimento este que está baseado em informações empíricas, orientado na prática e, no caso das populações

\footnotetext{
"Autora para correspondência: betabarboza@gmail.com Editora responsável: Maria Franco Trindade Medeiros Recebido: 7 maio 2011; aceito: 22 set. 2011.
}

costeiras, engloba saberes sobre o comportamento dos peixes, o ambiente marinho e as interações neste ecossistema (Ruddle 1994; Hanazaki 2002; Thé et al. 2003).

Contudo, combinar o saber local com o conhecimento científico não é tarefa simples. Requer o delineamento de metodologias que integrem os dados e informações de cada tipo de conhecimento (Freire \& García-Allut 1999; ValboJorgensen \& Poulsen 2000). Para Batista et al. (2004), as etnociências representam a forma atual de incorporação destes saberes no conjunto de conhecimentos técnicocientíficos para subsidiar as políticas públicas no manejo pesqueiro regional. Os estudos etnobiológicos em geral incluem o levantamento de espécies e "etnoespécies" e têm contribuído para planos de manejo e conservação de ecossistemas (Begossi 1993), através de modelos de gerenciamento de recursos naturais por povos nativos (Ruddle 1994; Posey 1990; Begossi et al. 1999; Aswani \& Hamilton 2004). Begossi (2004) atribui como principal objetivo da etnobiologia a compreensão da percepção humana sobre os recursos naturais, ou seja, os processos empregados na classificação dos elementos presentes nos ecossistemas. Nesse sentido, a etnobiologia apresenta-se como um amplo campo de estudo formado por vários ramos, com destaque para a etnoictiologia, que trata das inter-

Sitientibus série Ciências Biológicas 11(2): 133-141. 2011. 
relações entre homens e peixes (Marques 1995).

No Brasil, as pesquisas etnoictiológicas envolvem conhecimento tradicional acerca de hábitos alimentares dos peixes (Marques 1995; Paz \& Begossi 1996; Costa-Neto \& Marques 2000a, Costa-Neto 2001; Silvano \& Begossi 2002; Mourão \& Nordi 2003; Batistella et al. 2005), movimentos migratórios (Costa-Neto \& Marques 2000b; Costa-Neto et al. 2002; Silvano \& Begossi 2002; Mourão \& Nordi 2003), uso de hábitats (Paz \& Begossi 1996; Costa-Neto \& Marques 2000b; Costa-Neto 2001; Costa-Neto et al. 2002; Silvano \& Begossi 2002; Thé et al. 2003; Pinheiro 2004), etologia (CostaNeto \& Marques 2000a,b; Costa-Neto 2001; Mourão \& Nordi 2003; Silva \& Montag 2003) e reprodução (CostaNeto \& Marques 2000b; Costa-Neto 2001; Costa-Neto et al. 2002; Mourão \& Nordi 2003). Os pescadores também empregam o uso dos conhecimentos sobre peixes como indicadores de mudanças ecológicas nos sistemas aquáticos (Almeida \& Pinheiro 2005).

Desta forma, o presente estudo pretende investigar o conhecimento de pescadores artesanais da vila dos Pescadores e vila Bonifácio, localizadas na Reserva Extrativista (RESEX) Marinha Caeté-Taperaçu, Bragança (Pará), acerca de informações do comportamento, usos de hábitat e migração dos peixes da família Sciaenidae: corvina (Cynoscion microlepidotus Cuvier, 1830), cururuca (Micropogonias furnieri Desmarest, 1823), gó (Macrodon ancylodon Bloch \& Schneider, 1801) e pescada amarela
(Cynoscion acoupa Lacépè, 1802). Destaca-se no presente trabalho o papel fundamental da etnoictiologia na obtenção de dados plausíveis para o manejo da pesca a partir do conhecimento de pescadores.

\section{Material e Métodos}

Coleta dos dados. A área de estudo pertence a Reserva Extrativista Marinha Caeté-Taperaçu, no município de Bragança, estado do Pará, criada em maio de 2005 e que abrange uma área de aproximadamente 42.068 ha (Brasil 2005). De acordo com o SNUC (2000) a Reserva Extrativista é uma área utilizada por populações extrativistas tradicionais, cuja subsistência baseia-se no extrativismo e, complementarmente, na agricultura de subsistência e na criação de animais de pequeno porte, e tem como objetivos básicos proteger os meios de vida e a cultura dessas populações, e assegurar o uso sustentável dos recursos naturais da unidade. Fazem parte da Resex Caete-Taperaçu a vila dos Pescadores (0051'07.0'S, 046³6'02.5”W) e a vila Bonifácio (0050'58.9'’S, 046³6'28.7’'W) (Figura 1).

Os primeiros entrevistados foram escolhidos aleatoriamente. Em seguida, foi adotada a amostragem do tipo "snow ball" (Bailey 1994 apud Albuquerque \& Lucena 2004), que consiste na indicação dos novos informantes pelos próprios entrevistados. No total, foram empregados

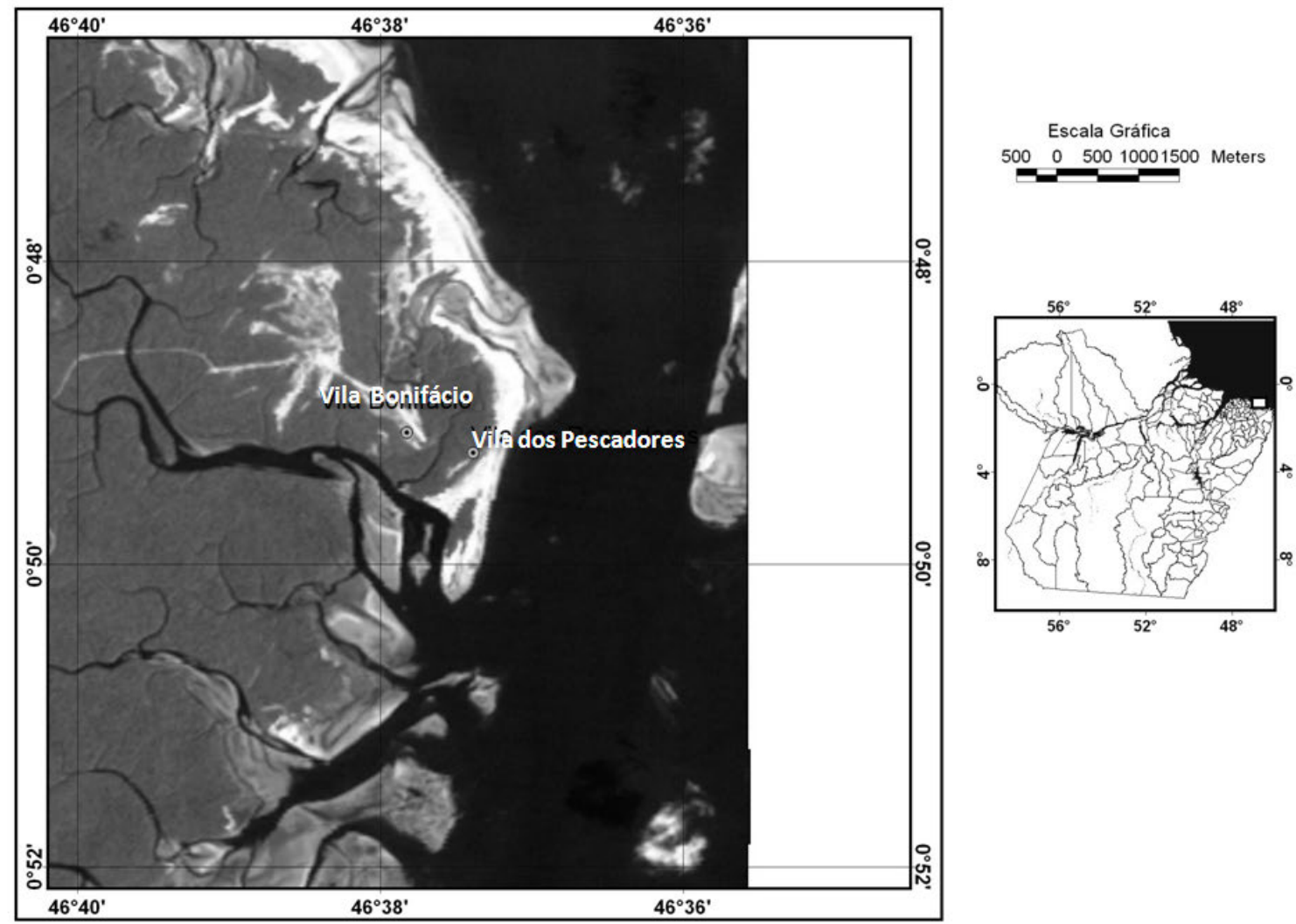

Figura 1. Área de estudo (Imagem cedida pelo Laboratório de Análise de Imagens do Trópico Úmido - LAIT, UFPA).

Sitientibus série Ciências Biológicas 11(2): 133-141. 2011. 
74 formulários semiestruturados (Viertler 2002) entre os pescadores da vila dos Pescadores e vila Bonifácio no período de julho a agosto de 2005 , considerando um pescador por domicílio, representando $40 \%$ das famílias nas comunidades estudadas.

O formulário incluiu perguntas sobre hábitats utilizados e movimentos migratórios dos peixes corvina (Cynoscion microlepidotus), cururuca (Micropogonias furnieri), gó (Macrodon ancylodon) e pescada-amarela (Cynoscion acoupa). Tais espécies foram selecionadas com base em dois critérios: 1- Verificação da existência de informações ecológicas na literatura científica para essas espécies na área de estudo; e 2- Importância do ponto de vista sócio-econômico destas espécies para os pescadores das vilas estudadas.

As citações dos pescadores durante as entrevistas acerca do comportamento de peixes da região foram registradas e utilizadas neste artigo. Os dados referentes aos hábitats ocupados pelos peixes foram complementados por um mapa (Figura 2) elaborado por um pescador experiente - informante-chave (Hays 1976; Marques 1995), contendo os pesqueiros citados pelos pescadores durante as entrevistas. O termo "pesqueiros" compreende uma denominação própria reconhecida entre os pescadores de Ajuruteua para definir os principais pontos de pesca utilizados.

Em dezembro de 2005, foram realizadas duas excursões embarcadas a fim de obter as coordenadas geográficas de alguns pesqueiros e pontos de referência para a pesca, descritos neste mapa. Apesar dos pescadores também utilizarem pesqueiros distantes da costa ("mar aberto"), as viagens foram realizadas apenas em áreas próximas à costa. Durante estas excursões embarcadas, um pescador experiente indicou in loco os pesqueiros apontados no mapa, além de outros pontos importantes, os quais foram registrados em um aparelho receptor de GPSGlobal Position System (Close \& Hall 2005).

Armazenamento e tratamento dos dados. Empregouse um banco de dados e os resultados relacionados a aspectos reprodutivos dos peixes foram organizados em uma tabela de cognição comparada (Marques 1995), onde trechos das entrevistas registradas são comparados com trechos da literatura científica (Costa-Neto \& Marques 2000b). As coordenadas geográficas dos principais pontos pesqueiros e alguns pontos de referência para a pesca local foram plotados em um mapa georreferenciado de Bragança no Laboratório de Análises de Imagens do Trópico Úmido (LAIT-UFPA).

\section{Resultados e Discussão}

Etologia. Durante as entrevistas, os pescadores citaram exemplos de padrões comportamentais de peixes

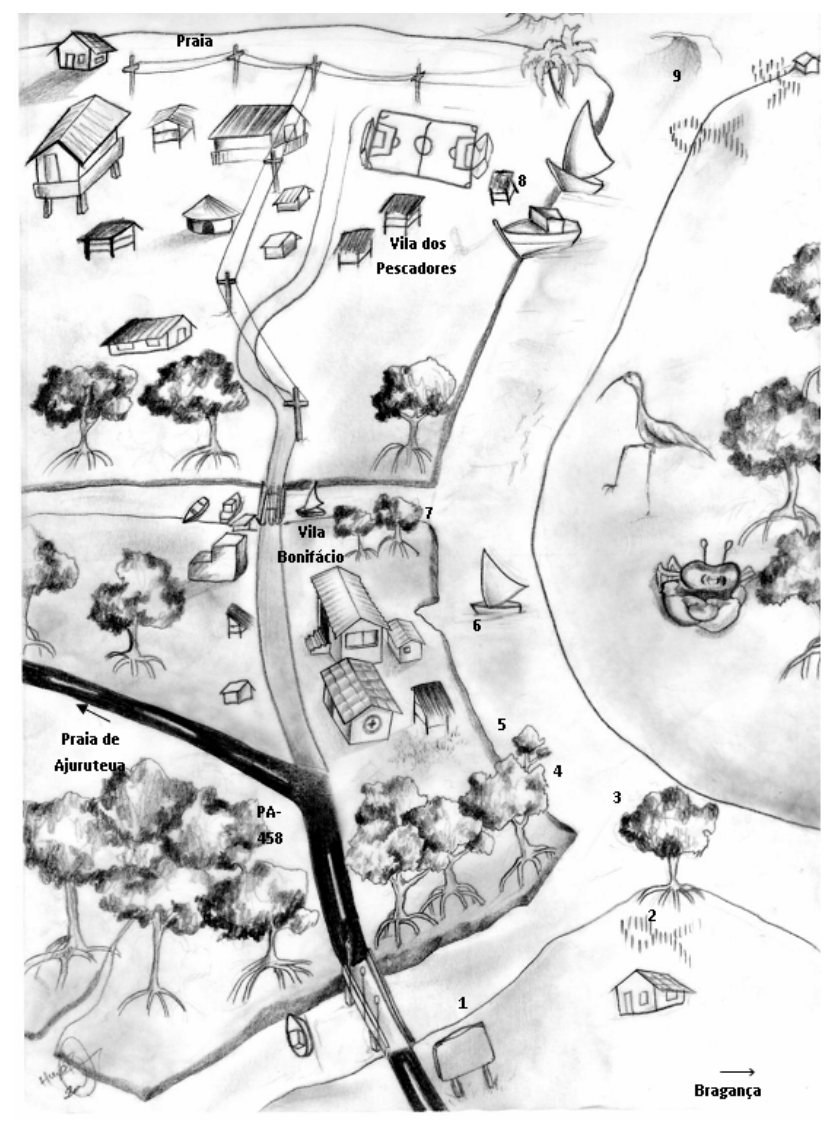

Figura 2. Croqui adaptado de um mapa confeccionado por um pescador de Ajuruteua com os principais pesqueiros, micro-hábitats e pontos de referência utilizados na pesca artesanal em Ajuruteua, Pará: 1- Furo Grande; 2- Ilha do Guará; 3- Emburateua da Pata; 4Igarapé do Poço Grande; 5- Emburateua do Braço; 6- Portinho; 7Maguari; 8- Porto da vila dos Pescadores e 9- Pontinha (Arte: Hugo Peres, 2006).

relacionados a aspectos fisiológicos, períodos de atividade e relações interespecíficas, os quais foram organizados na Tabela 1.

A frase "Pesco à noite; o peixe fica mais burro" foi citada por um pescador experiente e se refere a diferenças no padrão de atividades de peixes observado pelos pescadores de Ajuruteua. A presença de diferenças no padrão de movimento horizontal dos peixes incutida na frase acima já foi pesquisada por estudiosos no estuário do rio Caeté: Krumme et al. (2004), em estudos sobre mudanças em comunidades de peixes (Cathorops sp., Colomesus psittacus Bloch \& Schneider, 1801, Hexanematichthys couma, Vanclennes 1840, Anchovia clupeoides Swainson, 1829, Mugil spp., Anableps anableps Linnaeus, 1758) verificaram uma combinação de dois fatores (maré e período do dia) na estruturação dos cardumes. Colomesus psittacus, por exemplo, apresentou padrão de atividade diurno. Krumme \& Saint-Paul (1993) registraram diferenças no padrão de movimento horizontal dos cardumes durante o dia e a noite, referentes à migração de peixes no estuário do rio Caeté.

Sitientibus série Ciências Biológicas 11(2): 133-141. 2011. 
Tabela 1. Comportamento de alguns representantes da ictiofauna de Ajuruteua, Pará, Brasil, segundo os pescadores artesanais locais.

\begin{tabular}{|c|c|}
\hline Citações dos pescadores locais & Fenômenos percebidos \\
\hline "Pesco a noite; o peixe fica mais burro." & Período de atividade \\
\hline $\begin{array}{l}\text { "Piolho: peixe que chupa sangue e mata. Fica pregado na } \\
\text { aba, no lombo da pescada." }\end{array}$ & Parasitismo \\
\hline "Piolho de cação só sai quando tá grande." & Comensalismo \\
\hline "Peixe de ferrão [bagre, cangatã] cria o peixe na boca." & Cuidado parental \\
\hline $\begin{array}{l}\text { "No barco, escuto o ronco da cururuca [Micropogonias } \\
\text { furnieri] no fundo." }\end{array}$ & Fisiologia \\
\hline
\end{tabular}

Na segunda frase, o termo "piolho" ("Piolho: peixe que chupa sangue e mata. Fica, pregado na aba, no lombo da pescada"), utilizado por um pescador, pode se referir a relação de parasitismo entre crustáceos isópodas e peixes, verificada por Barnes (1974).

Em relação à citação de um pescador ("Piolho de cação só sai quando tá grande"), há na literatura informações acerca de rêmoras (Echeneis naucrates Linnaeus, 1758) que se encontram aderidas a algumas espécies de tubarões e outros peixes (Cervigón 1994).

O comportamento de cuidado parental através da incubação de ovos na cavidade bucal encontra-se documentado para alguns bagres da região bragantina (Krumme et al. 2004) e foi observado por vários pescadores, como pode-se constatar na frase: "Peixe de ferrão cria o peixe na boca".

O "ronco da cururuca" relatado por pescadores de Ajuruteua pode estar relacionado às vibrações produzidas por músculos especiais ligados à bexiga natatória que funciona como órgão de ressonância, produzindo sons característicos entre os peixes da família Sciaenidae (Menezes \& Figueiredo 1985). É interessante destacar ainda os sons produzidos por alguns peixes da família Haemulidae, conhecidos como roncadores, devido à capacidade de amplificação dos sons promovida pela bexiga natatória ao moerem os alimentos (Espirito-Santo \& Isaac 2005). CostaNeto (2001) reuniu alguns caracteres etológicos de peixes reconhecidos pelos pescadores de Siribinha (Bahia) em 18 etnocategorias comportamentais, entre elas "peixes que fazem zoada", "peixes que têm cantiga" e "peixes que roncam". No estuário do rio Mamanguape (Paraíba), Mourão \& Nordi (2003) subcategorizaram em "peixes que roncam" oito espécies de peixes apontadas pelos pescadores locais, incluindo a cururuca, mencionada pelos pescadores que participaram do presente estudo.

Uso de hábitats. Entre os pescadores artesanais de Ajuruteua, foram registradas 10 unidades espaciais gerais (ponta, boca, fora, canal, furo, cabeceira, quebrada, emburateua, lajeiro e poço). Destas, algumas são subcategorizadas e reconhecidas como importantes pesqueiros, pontos de referência comuns e micro-hábitats, ecozonas ou etno-hábitats (Mourão \& Nordi 2003; Thé et al. 2003) e utilizados em suas atividades pesqueiras (Figuras 2 e 3 ). Costa-Neto (2001) identificou 22 unidades espaciais percebidas, nomeadas e utilizadas pelos pescadores de Siribinha (BA).

O termo científico micro-hábitat se refere a lugares ocupados pelos peixes por fornecerem abrigo, alimentação e/ou locais de reprodução (Figuras 2 e 3). Posey (1997) define ecozonas como áreas ecológicas reconhecidas em outros sistemas culturais que podem ou não coincidir com as tipologias científicas. Estudos etnoictiológicos vêm revelando o conhecimento detalhado de pescadores sobre hábitat de peixes (Paz \& Begossi 1996).

O termo "emburateua", por exemplo, é bastante utilizado em Ajuruteua para definir os pontos na margem do estuário onde há grande quantidade de peixes devido ao abrigo originado por troncos de árvores de manguezais caídos no rio. São naturais ou podem ser criados artificialmente através da derrubada de árvores. Alguns emburateuas recebem nomes próprios (emburateua da pata, do braço) (Figura 3) e são citados como áreas de desenvolvimento dos peixes juvenis em Ajuruteua, como pode ser verificado em algumas falas de pescadores:

\section{"Emburateua é onde o pau cai." \\ “... (Emburateua) é o criadouro dos peixes." \\ "O peixe se cria nos emburateua, depois sai pra fora."}

Maneschy (1995) também documentou o uso do termo emburateua, de origem indígena, entre os pescadores de Ajuruteua para designar os trechos nos rios onde se concentravam pedaços de galhos de árvores e eram próprios para a captura de peixes. Segundo Costa-Neto \& Marques (2000b), os pescadores do Conde (BA) manejam ambientes artificiais através da derrubada de galhos de árvores de manguezais na água, de maneira a propiciar abrigo e alimento aos peixes.

Outro etno-hábitat bastante utilizado localmente são os "lajeiros", substratos rochosos situados em lugares fundos que fornecem alimento e proteção para peixes maiores ou em fase adulta. A cururuca foi amplamente associada aos lajeiros por utilizar esse espaço para mariscar sururu. Os "poços" estão situados no estuário e junto com os lajeiros são considerados área de desova. Os trechos das entrevistas inseridos abaixo exemplificam a percepção nativa acerca da importância dos poços e lajeiros como áreas de 

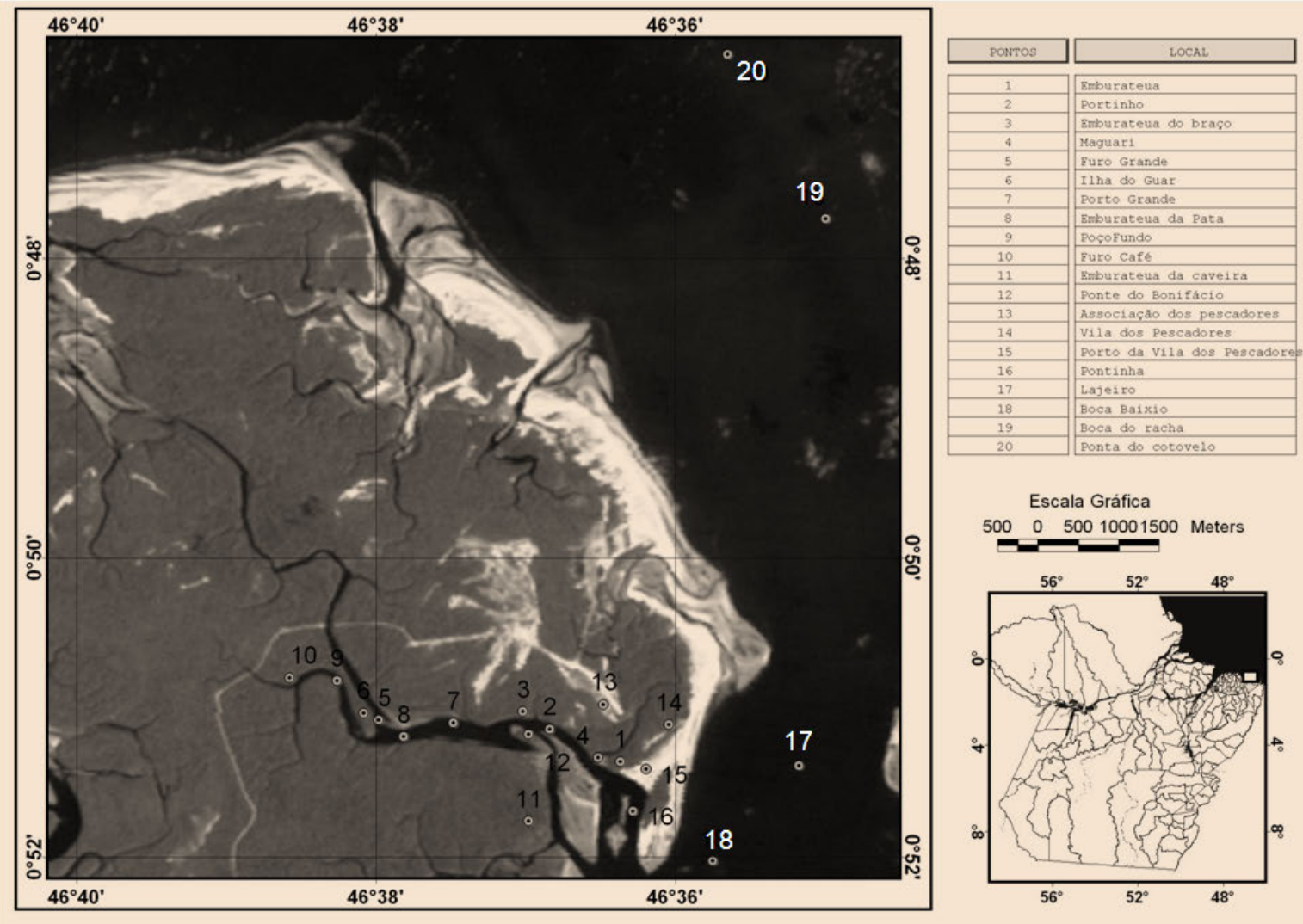

Figura 3. Mapa georreferenciado com as coordenadas geográficas dos principais pesqueiros, micro-hábitats e pontos de referência apontados no croqui da Figura 2 (Imagem cedida pelo Laboratório de Análise de Imagens do Trópico Úmido, - LAIT, UFPA)

desova dos peixes:

"A pescada desova no lajeiro e os filhos vêm pro igarapé".

"Os peixes desovam no poço; pode ser por causa do sossego com outros peixes".

Maneschy (1995) definiu poços como áreas fundas próximas à praia em Ajuruteua. Alguns micro-hábitats também são considerados importantes pontos de pesca. Os emburateua, por exemplo, concentram pescadores de linha e anzol. Contudo, de acordo com os pescadores locais, a pesca do tipo bate-pau vem afugentando os peixes dessas áreas e, consequentemente, afasta os pescadores que usam linha e anzol. O bate-pau consiste em deslocar os peixes de seus refúgios através da produção de barulho na água, provocado por "batidas" repetitivas de pedaços de madeira nos emburateua. Este tipo de pesca já foi mencionado por Maneschy (1995) entre os pescadores de Ajuruteua. Segundo a autora, nesta pescaria havia a participação dos "bulheiros": pescadores munidos de uma vara que batiam na água para deslocar os peixes em direção a uma rede levada por outros pescadores. O bate-pau é conhecido também como "batição" e "bate-vara" e é utilizado nas pescarias de quelônios no Parque Nacional do Jaú (Amazonas) (Pezzuti et al. 2004) e de pirarucu (Arapaima gigas Cuvier, 1817) na Reserva de Desenvolvimento Sustentável Mamiruá (Amazonas) (Crampton et al. 2004b).

Movimentos migratórios. Constatou-se entre os pescadores de Ajuruteua, a percepção da influência sazonal nos deslocamentos realizados pelos peixes, cuja abundância na região é atribuída ao período chuvoso. Outros aspectos reconhecidos pelos pescadores, como movimento das marés, reprodução, busca por alimento (comedia), fuga de predadores e proteção contra alguns tipos de pescarias, também desempenham importante papel na distribuição espacial e temporal dos peixes (Tabela 2). De fato, um conjunto de autores já registrou vários fatores propulsores dos deslocamentos de peixes, como os reconhecidos pelos pescadores de Ajuruteua, conforme é exemplificado abaixo.

Influência sazonal e regime hidrológico. Silvano \& Begossi (2002) verificaram, entre os pescadores do rio Piracicaba, o uso de pistas climáticas na previsão dos períodos de abundância de peixes e o reconhecimento de espécies de peixes migratórias e sedentárias, bem como dos padrões de movimentos migratórios entre alguns peixes. Os pescadores do rio Piracicaba também associaram o período chuvoso à abundância de peixes migratórios. Em estudo realizado sobre as mudanças sazonais na composição das espécies de peixes do estuário do rio Caeté, Barletta et al. (2005) registraram a flutuação sazonal da

Sitientibus série Ciências Biológicas 11(2): 133-141. 2011. 
Tabela 2. Informações dos pescadores artesanais de Ajuruteua, Pará, Brasil, sobre a distribuição espacial e temporal dos peixes.

\begin{tabular}{|c|c|c|}
\hline Citações dos pescadores & $\begin{array}{l}\text { Razões apontadas } \\
\text { (pescadores) }\end{array}$ & $\begin{array}{l}\text { Correspondência } \\
\text { científica }\end{array}$ \\
\hline $\begin{array}{l}\text { "No inverno, dá muito peixe; o preço cai." } \\
\text { "Época que dá mais peixe é abril e maio." } \\
\text { "Todo peixe é por época ; no inverno, se deslocam mais da } \\
\text { moradia." } \\
\text { "No inverno, todo tempo dá muito, todo tempo pega; na } \\
\text { safra', pega mais." } \\
\text { "As pescaria ocorrem mais no inverno; sardinas correm } \\
\text { atrás da chuva e os peixes atrás da sardina." } \\
\text { "Gó na descida da chuva (começo do inverno) entra no rio } \\
\text { de todo tamanho." }\end{array}$ & Inverno e Chuva & $\begin{array}{l}\text { Influência sazonal } \\
\text { e pluviosidade } \\
\text { (regime hidrológico) }\end{array}$ \\
\hline $\begin{array}{l}\text { "Quando vem a água preta da Amazônia, vem muito } \\
\text { peixe." } \\
\text { "A gó entra no rio quando a água está doce de qualquer } \\
\text { tamanho." }\end{array}$ & $\begin{array}{l}\text { Água preta e } \\
\text { Água doce }\end{array}$ & Aporte de nutrientes \\
\hline $\begin{array}{l}\text { "A pescada desova no lajeiro e os filhos vêm pro igarapé; } \\
\text { quando cresce volta." } \\
\text { "No verão a gó tá pouca, tá desovando na cabeceira." }\end{array}$ & Desova & Reprodução \\
\hline $\begin{array}{l}\text { "Em fevereiro , a gó se muda para fora para pegar a } \\
\text { comedia e não pega no curral." }\end{array}$ & Comedia & Alimentação \\
\hline $\begin{array}{l}\text { "O peixe fica na cabeceira pequeno; sai pra fora quando tá } \\
\text { maior, se não o graúdo come ele." }\end{array}$ & Fuga de predadores & $\begin{array}{l}\text { Ciclo de vida } \\
\text { (variação ontogenética } \\
\text { no padrão migratório) }\end{array}$ \\
\hline $\begin{array}{l}\text { "A pescada pequena só aparece no rio; pescam de rede no } \\
\text { lajeiro e não pega pequena, e não acha pescada grande nos } \\
\text { igarapés por isso acho que pequena dá nos igarapés, cresce e } \\
\text { sai pros lajeiros." } \\
\text { "Cururuca: sai do mar pequena e entra no rio." } \\
\text { "Curvina cresce e sai do rio pra fora." }\end{array}$ & $\begin{array}{l}\text { Tamanho do peixe e } \\
\text { mudança no local onde } \\
\text { vive }\end{array}$ & \\
\hline $\begin{array}{l}\text { "O peixe sente a rede apoitada }{ }^{2}, \text { timbó }^{3} \text { e sai pra fora." } \\
\text { "Se fica na cabeceira, matam de tapagem"." }\end{array}$ & Fuga de pescarias & Artes de pesca \\
\hline
\end{tabular}

${ }^{1} \mathrm{O}$ período de maior abundância dos peixes é conhecido pelos pescadores se Ajuruteua como safra, tendo cada peixe sua safra.

${ }^{2}$ Redes apoitadas ou ferreadas são redes que ficam presas no fundo, não são levadas pela maré, conforme aponta a fala dos próprios pescadores de Ajuruteua: "Rede apoitada, coloca pedra na rede que fica escorada, ferreada no fundo", "Apoitar é colocar pedra na rede", "Pesca ferreada: ancora no fundo $(200 \mathrm{~m})$, fica presa contra maré, pega peixe miúdo de ferrão."

${ }^{3}$ Timbó são venenos de origem vegetal utilizados na pesca de igarapés (Cabalzar 2005).

${ }^{4}$ A tapagem é uma armadilha usada por pescadores nos braços de mar e em foz de pequenos rios e igarapés que sofrem influência dos fluxos e refluxos da maré (Barletta et al. 1998; Nery 1995). Maneschy (1995) descreveu a tapagem de igarapés em Ajuruteua: estacas são colocadas na entrada de um igarapé durante as marés baixas, quando a maré enche a rede é estendida sobre as varas, prendendo os peixes que vão entrando no igarapé durante a maré cheia.

salinidade como principal fator que estrutura a assembleia de peixes nesse sistema estuarino. De acordo com Camargo \& Isaac (2003), a tolerância e preferência por certos teores de salinidade é o fator ambiental mais relevante na distribuição da fauna estuarina. Batista et al. (2004) apontam o inverno como principal período de safra da pesca artesanal estuarina litorânea, quando a forte descarga do rio Amazonas desloca a água salobra para leste do estado do Pará.

Aporte de nutrientes. A "água preta" citada pelos pescadores pode ser considerada como uma referência ao grande aporte de matéria orgânica trazida pela descarga fluvial, cuja intensidade apresenta-se maior no período chuvoso. De fato, Dittmar (1999 apud Wolff et al. 2000) registrou maior concentração de nutrientes no estuário do rio Caeté durante o período chuvoso. A incidência de espécies de água doce e salobra também se eleva durante a estação chuvosa nas zonas estuarinas tropicais, de acordo com Barletta et al. (1998). Ainda, as informações científicas para a pescada-amarela apontam uma certa tolerância a baixos níveis de salinidade, com pico de abundância na estação chuvosa (Camargo 1999; Barletta-Bergan et al. 2002; Gomes 2003).

Em Siribinha, Bahia, fenômenos meteorológicos como tempestades e o período de surgimento do "verdete" (provável boom fitozooplanctônico) são fatores reconhecidos entre os pescadores como significativos na distribuição dos peixes (Costa-Neto 2001).

Maré. Em relação à influência da maré sobre os padrões migratórios de peixes, Krumme (2004) verificou que no estuário do rio Caeté os peixes geralmente se deslocam junto com a maré. 
Ciclos de vida. Já os estudos de estrutura populacional realizados no estuário do rio Caeté revelam que os peixes gó (Macrodon ancylodon), curuca (Stellifer rastrifer Jordan, 1889; S. naso Jordan, 1889), uricica-amarela (Cathorops spixii Agassiz, 1829) e rebeca (Aspredo aspredo Linnaeus, 1758) apresentam diferentes estratégias biológicas quanto à distribuição espacial e abundância relativa durante seus respectivos ciclos de vida (Camargo \& Isaac 1998). Camargo (1999) estudou a biologia e estrutura populacional de alguns peixes da família Sciaenidae e concluiu que a gó se desloca entre as áreas mais externas e internas do estuário, de acordo com as fases do seu ciclo de vida e com as mudanças nas condições ambientais, em especial a entrada e saída das águas do mar, em virtude dos movimentos das marés. Os pequenos recrutas toleraram a baixa salinidade da área do rio, já os grandes indivíduos demonstraram uma marcante preferência pela baía e hábitats costeiros (Camargo \& Isaac 1998, 2005). Os jovens de cururuca são frequentes nas regiões internas dos estuários, os adultos nas regiões costeiras (Sanyo 1998 apud Camargo \& Isaac 2003) e suas larvas são dependentes de baixa salinidade (Barletta-Bergan et al. 2002), e portanto também associadas ao estuário. Somente exemplares jovens de corvina habitam a parte mais interna das regiões estuarinas (Camargo 1999).

Reprodução. Barletta et al. (2005) revelam que as mudanças sazonais nas assembleias de peixes estuarinos podem ser determinadas pela combinação de flutuações temporais da abundância de espécies de peixes induzida pela chuva, reprodução e recrutamento de espécies estuarinas, marinhas e de água doce.

\section{Conclusões}

Os resultados apresentados revelam o detalhamento incutido nas observações dos pescadores de Ajuruteua sobre aspectos comportamentais dos peixes. Foram relatados fenômenos etológicos relacionados com fisiologia, reprodução, parasitismo e comensalismo, inclusive com respaldo na literatura científica.

Os pescadores indicaram ainda as principais unidades espaciais ocupadas pelos peixes e prováveis razões (bióticas e abióticas) para o deslocamento entre essas unidades. O reconhecimento desses micro-hábitats tem fundamental importância na realização de suas atividades pesqueiras.

Este estudo vem demonstrar o saber acurado dos pescadores de Ajuruteua, o qual deve ser inserido no gerenciamento dos recursos de pesca da região bragantina a título de otimizar a produção pesqueira artesanal local, com grande potencial de aplicação considerando a área estudada uma Reserva extrativista.

\section{Agradecimentos}

Aos pescadores de Ajuruteua, principais responsáveis por este estudo; à pesquisadora Myrian Barboza, pela revisão do texto; aos pesquisadores Pedro Walfir e Francisco Costa, do Laboratório de Análises de Imagens do Trópico Úmido (LAIT-UFPA), pela ajuda com as imagens de satélite e ao desenhista Hugo Peres pela confecção do croqui. À CAPES, pela concessão de bolsa de mestrado. Ao programa de bolsas BECA do Instituto Internacional de Educação do Brasil e a Fundação Gordon e Betty Moore pelo apoio e bolsa na modalidade mestrado.

\section{REFERÊNCIAS}

Albuquerque, U.P. \& Lucena, R.F.P. 2004. Métodos e técnicas para coleta de dados. In: U.P. Albuquerque, R.F.P. Lucena \& L.V.F.C. Cunha (orgs), Métodos e Técnicas na Pesquisa Etnobotânica. Editora Livro Rápido/NUPEEA, Recife, p. 3762.

Almeida, I.C.S. \& Pinheiro, C.U.B. 2005. Uso do conhecimento tradicional na identificação de indicadores de mudanças ecológicas nos ecossistemas aquáticos da região lacustre de Penalva, Área de Proteção Ambiental da Baixada MaranhenseI. Peixes. In: A.G. Alves, R.F.P. Lucena \& U.P. Albuquerque (eds), Atualidades em Etnobiologia e Etnoecologia. SBEE, Recife, p. 61-80.

Aswani, S. \& Hamilton, R.J. 2004. Integrating indigenous ecological knowledge and customary sea tenure with marine and social science for conservation of bumphead parrotfish (Bolbometopon muricatum) in the Roviana Lagoon, Solomon Islands. Environmental Conservation 31(1): 69-83.

Barletta, M.; Barletta-Bergan, A. \& Saint-Paul, U. 1998. Description of the fisheries structure in the mangrovedominated region of Bragança (State of Pará, North Brazil). Ecotropica 4(1-2): 41-53.

Barletta, M.; Barletta-Bergan, A.; Saint-paul, U. \& Hubold, G. 2005. The role of salinity in structuring the fish assemblages in a tropical estuary. Journal of Fish Biology 66: 45-72.

Barletta-Bergan, A.; Barletta, M. \& Saint-Paul, U. 2002. Structure and seasonal dynamics of larval fish in the Caeté River estuary in North Brazil. Estuarine Coastal and Shelf Science 54: 193-206.

Barnes, R. 1974. Zoologia de los Invertebrados. 3 ed. Nueva Editorial, México.

Barthem, R.B. \& Fabré, N.N. 2004. Biologia e diversidade dos recursos pesqueiros da Amazônia. In: M.L. Ruffino (coord.). A Pesca e os Recursos Pesqueiros na Amazônia Brasileira. Ibama/ProVárzea, Manaus, p. 17-62.

Batista, V.S.; Isaac, V.J. \& Viana, J.P. 2004. Exploração e manejo dos recursos pesqueiros da Amazônia. In: M.L. Ruffino (coord.). A Pesca e os Recursos Pesqueiros na Amazônia Brasileira. Ibama/ProVárzea, Manaus, p. 63-151.

Batistella, A.M.; Castro, C.P. \& Vale, J.D. 2005. Conhecimento dos moradores da comunidade de Boas Novas, no lago Januacá Amazonas, sobre os hábitos alimentares dos peixes da região. Acta Amazonica 35(1): 51-54.

Begossi, A. 1993. Ecologia humana: um enfoque das relações homem ambiente. Interciência 18(3): 121-132.

Begossi, A. 2004. Ecologia humana. In: A. Begossi (org.), Ecologia de Pescadores da Mata Atlântica e da Amazônia. Hucitec/

Sitientibus série Ciências Biológicas 11(2): 133-141. 2011. 
Unicamp/USP/Fapesp, São Paulo, p. 13-36.

Begossi, A. 2006. Temporal stability in fishing spots: conservation and co-management in Brazilian artisanal coastal fisheries. Ecology and Society 11(1): 5.

Begossi, A.; Silvano, R.A.M.; Amaral, B.D. \& Oyakawa, O.T. 1999. Uses of fish and game by inhabitants of an extractive reserve (Upper Juruá, Acre, Brazil). Environment, Development and Sustainability 1: 73-93.

Brasil 2005. Presidência da República. Decreto de 20 de maio de 2005.

Cabalzar, A. 2005. Peixe e Gente no Rio Tiquié: conhecimentos tukano e tuyuka, ictiologia e etnologia. ISA, São Paulo.

Camargo, M. 1999. Biologia e Estrutura Populacional das Espécies da Família Sciaenidae (Pisces: Perciformes), no Estuário do Rio Caeté Município de Bragança, Pará, Brasil. Dissertação de Mestrado. Universidade Federal do Pará/ Museu Paraense Emílio Goeldi.

Camargo, M. \& Isaac, V.J. 1998. Populations structure of fish fauna in the estuarine area of Caeté River, Pará, Brazil. Acta Scientiarum 20(2): 171-177.

Camargo, M. \& Isaac, V.J. 2003. Ictiofauna estuarina. In: M.E.B. Fernandes (org.), Os Manguezais da Costa Norte Brasileira. Fundação Rio Bacanga, Maranhão, p. 105-142.

Camargo, M. \& Isaac, V.J. 2005. Reproductive biology and spatio-temporal distribution of Stellifer rastrifer, Stellifer naso and Macrodon ancylodon (Sciaenidae) in the Caeté estuary, northern Brazil. Brazilian Journal of Oceanography 53(1/ 2): $13-21$

Carlsson, L. \& Berkes, F. 2005. Co-management: concepts and methodological implications. Journal of Environmental Management 75: 65-76.

Castro, F. 2004. Níveis de decisão e o manejo de recursos pesqueiros. In: A. Begossi (org.), Ecologia de Pescadores da Mata Atlântica e da Amazônia. Hucitec/Unicamp/USP/ Fapesp, São Paulo, p. 255-283.

Cervigón, F. 1994. Los Peces Marinos de Venezuela. Vol. 3.2 ed. Ex-Libris, Caracas.

Close, C.H. \& Hall, G.B. 2005. A GIS-based protocol for the collection and use of local knowledge in fisheries management planning. Journal of Environmental Management 20: 1-12.

Costa-Neto, E.M. 2001. A Cultura Pesqueira do Litoral Norte da Bahia. Etnoictiologia, Desenvolvimento $e$ Sustentabilidade. EDUFBA/EDUFAL, Salvador e Maceió.

Costa-Neto, E.M. \& Marques, J.G.W. 2000a. Etnoictiologia dos pescadores artesanais de Siribinha, município de Conde (Bahia): aspectos relacionados com a etologia dos peixes. Acta Scientiarum. Biological Sciences 22(2): 553-560.

Costa-Neto, E.M. \& Marques, J.G.W. 2000b. Conhecimento ictiológico tradicional e a distribuição temporal e espacial de recursos pesqueiros pelos pescadores de Conde, estado da Bahia, Brasil. Etnoecológica 4(6): 56-68.

Costa-Neto, E.M.; Dias, C.V. \& Melo, M.N. 2002. O conhecimento ictiológico tradicional dos pescadores da cidade de Barra, região do médio São Francisco, estado da Bahia, Brasil. Acta Scientiarum. Biological Sciences 24(2): 561-572.

Crampton, W.G.R.; Castello, L. \& Viana, J.P. 2004a. Fisheries in the Amazon várzea: historical trends, current status and factors affecting sustainability. In: People in Nature: wildlife conservation in South and Central America. Columbia University Press, New York, p. 76-98.

Crampton, W.G.R.; Viana, J.P.; Castello, L. \& Damasceno,
J.M. 2004b. Fisheries management in the Mamirauá sustainable development reserve. In: People in Nature: wildlife conservation in South and Central America. Columbia University Press, New York: 99-122.

Espírito-Santo, R.V. \& Isaac, V.J. (coords) 2005. Peixes e Camarões do Litoral Bragantino, Pará, Brasil. MADAM, Belém.

Freire, J. \& García-Allut, A. 1999. Integration of fishers' ecological knowledge in the fisheries biology and management. A proposal for the case of the artisinal coastal fisheries of Galicia (NW Spain). Ices Council Meeting Paper, ICES-CM, S: 7.

Gomes, G.F.E. 2003. Estudos Genéticos e Ecológicos em Peixes Cianídeos do Estuário do Rio Caeté, Bragança, Pará. Monografia de Graduação (Ciências Biológicas), Universidade Federal do Pará, Bragança.

Hanazaki, N. 2002. Conhecimento caiçara para o manejo dos recursos naturais. In: U.P. Albuquerque, A.G.C. Alves, A.C.B. Lins-Silva \& V.A. Silva (orgs), Atualidades em Etnobiologia e Etnoecologia. SBEE, Recife, p. 17-25.

Hays, T.E. 1976. An empirical method for the identification of covert categories in ethnobiology. American Ethnologist 3(3): 489-507.

Krumme, U. 2004. Patterns in tidal migration of fish in a Brazilian mangrove channel as revealed by a vertical split-beam echosounder. Fisheries Research 70(1): 1-15.

Krumme, U. \& Saint-Paul, U. 1993. Observations of fish migration in a macrotidal mangrove channel in Nothern Brazil using a 200-kHz split-beam sonar. Aquatic Living Resources 16(3): 175-184.

Krumme, U.; Saint-Paul, U. \& Rosenthal, H. 2004. Tidal and diel changes in the structure of a nekton assemblage in small intertidal mangrove creeks in northern Brazil. Aquatic Living Resources 17: 215-229.

Maneschy, M.C. 1995. Ajuruteua, uma Comunidade Pesqueira Ameaçada. Editora Universitária UFPA, Belém.

Marques, J.G.W. 1995. Pescando Pescadores: etnoecologia abrangente no baixo São Francisco Alagoano. NUPAUB/ USP, São Paulo.

Menezes, N.A. \& Figueiredo, J.L. 1985. Manual de Peixes Marinhos do Sudeste do Brasil. V. Teleostei (4). USP, São Paulo.

Mourão, J.S. \& Nordi, N. 2003. Etnoictiologia de pescadores artesanais no estuário do rio Mamanguape, Paraíba, Brasil. Boletim do Instituto de Pesca 29(1): 9-17.

Nery, A.C. 1995. Traços da tecnologia pesqueira de uma área de pesca tradicional na Amazônia-Zona do Salgado-Pará. Boletim do Museu Paraense Emilio Goeldi, Série Antropológica 11(2): 199-293.

Paz, V.A. \& Begossi, A. 1996. Ethnoichthyology of Gamboa fishermen of Sepetiba Bay, Brazil. Journal of Ethnobiology 16(2): 157-168.

Pezzuti, J.C.B.; Rebêlo, G.H.; Silva, D.F.; Lima; J.P. \& Ribeiro, M.C. 2004. A caça e a pesca no Parque Nacional do Jaú. In: S.H. Borge, S. Iwanaga, C.C. Durigan \& M.R. Pinheiro (eds), Janelas para a Biodiversidade no Parque Nacional do Jaú: uma estratégia para o estudo da biodiversidade na Amazônia. Fundação Vitória Amazônica, Manaus, p. 123230.

Pinheiro, L. 2004. Da ictiologia ao etnoconhecimento: saberes populares, percepção ambiental e senso de conservação em 
comunidade ribeirinha do rio Piraí, Joinville, estado de Santa Catarina. Acta Scientarium. Biological Sciences 26(3): 325334.

Posey, D.A. 1990. Introduction to ethnobiology: its implications and applications. In: D.A. Posey \& W. Overal (orgs), Ethnobiology: its implications and applications. Vol. 1. Museu Paraense Emilio Goeldi, Belém, p. 1-8.

Posey, D.A. 1997. Etnobiologia: teoria e prática. In: D. Ribeiro (ed.), Suma Etnológica Brasileira. Vol. 1. Etnobiologia. 3. ed. Editora Universitária UFPA, Belém, p. 1-15.

Ruddle, K. 1994. Local knowledge in the folk management of fisheries and coastal marine environments. In: C.L. Dyer \& J.R. Mcgoodwin (eds), Folk Management in the World's Fisheries: lessons for modern fisheries management. University Press of Colorado, Colorado, p. 161-206.

Sen, S. \& Nielsen, J.R. 1996. Fisheries co-management: a comparative analysis. Marine Policy 20(5): 405-418.

Silva, F.R. \& Montag, L.F. 2003. Etnoecologia de peixes em comunidades ribeirinhas da Floresta Nacional de Caxiuanã, município de Melgaço-PA. In: $6^{\circ}$ Seminário Estação Cientifica Ferreira Pena: dez anos de pesquisa na Amazônia contribuição e novos desafios. Belém.

Silvano, R.A.M. \& Begossi, A. 2002. Ethnoichthyology and fish conservation in the Piracicaba river (Brazil). Journal of Ethnobiology 22(2): 285-306.

SNUC (Sistema Nacional de Unidades de Conservação da Natureza) 2000. Lei No 9.985, de 18 de julho de 2000.

Thé, A.P.G.; Madi, E.F. \& Nordi, N. 2003. Conhecimento local, regras informais e uso do peixe na pesca local do Alto-Médio São Francisco. In: H.P. Godinho, \& A.L. Godinho (eds), Águas, Peixes e Pescadores do São Francisco das Minas Gerais. PUC Minas, Belo Horizonte.

Valbo-Jorgensen, J. \& Poulsen, A.F. 2000. Using local knowledge as a research tool in the study of river fish biology - experiences from the Mekong. Environment, Development, Sustainability 2(3-4): 253-276.

Viertler, R.B. 2002. Métodos antropológicos como ferramenta para estudos em etnobiologia e etnoecologia. In: M.C.M. Amorozo, L.C. Ming \& S.M.P. Silva (eds), Métodos de Coleta e Análise de Dados em Etnobiologia, Etnoecologia $e$ Disciplinas Correlatas. UNESP/CNPq, Rio Claro, p. 11-29.

Wolff, M.; Koch, V. \& Isaac. V.J. 2000. A trophic flow model of the Caeté mangrove estuary (North Brazil) with considerations for the sustainable use of its resources. Estuarine, Coastal and Shelf Science 50: 789-803. 